\title{
BRIEF
}

\section{Assessment of Impostor Phenomenon in Student Pharmacists and Faculty at Two Doctor of Pharmacy Programs} \author{
Lloyd, ${ }^{a}$ Sara Bonenfant, PharmD ${ }^{\mathrm{e}}$ \\ ${ }^{a}$ Northeast Ohio Medical University, Rootstown, Ohio \\ ${ }^{\mathrm{b}}$ Sullivan University, College of Pharmacy and Health Sciences, Louisville, Kentucky \\ ${ }^{\mathrm{c}}$ Associate Editor, American Journal of Pharmaceutical Education, Arlington, Virginia \\ ${ }^{\mathrm{d}}$ Life Alchemy LLC, Norway, Michigan \\ e Southwest General, Middleburg Heights, Ohio
}

Jaclyn Boyle, PharmD, MS, MBA, ${ }^{a}$ Daniel R. Malcom, PharmD,,${ }^{\text {bc }}$ Alex Barker, PharmD, ${ }^{\text {d }}$ Ramandeep Gill, ${ }^{\text {a }}$ Mackenzie

Corresponding Author: Jaclyn Boyle, Northeast Ohio Medical University, 4209 St. Rt. 44, Rootstown, OH 44272. Tel: 330-3256452. Email: Jboyle2@neomed.edu

Submitted November 13, 2020; accepted May 11, 2021; ePublished May 2021

Objective. The objective of this study was to evaluate the prevalence of impostor phenomenon (IP) in student pharmacists and faculty members at two educational institutions in the US.

Methods. An electronic self-report survey instrument including the validated Clance Impostor Phenomenon Scale (CIPS) was delivered anonymously from April 2020 to May 2020. Demographic data including age range, gender, and other characteristics were collected. CIPS scores were reported as overall mean (SD) and data were compared between institutions and demographic groups using Student's $t$ tests.

Results. The overall mean CIPS score for all survey respondents $(\mathrm{N}=209,35.5 \%$ response rate) was $63.8(\mathrm{SD}=15.1)$. Mean student pharmacist CIPS score for NEOMED was $64.7(\mathrm{SD}=14.4)$ vs. $63.8(\mathrm{SD}=16.1)$ for SUCOPHS, which was similar. Mean faculty CIPS score for NEOMED was 59.2 (SD=14.0) vs. 64.7 (SD=16.8) for SUCOPHS, which was similar. Mean CIPS score for the combined student pharmacist group (NEOMED and SUCOPHS) was 64.3 (SD=15.1) vs. $61.2(\mathrm{SD}=15.1)$ for the combined group of faculty members, which was similar. Overall, most respondents fell in the "moderate" to "frequent" CIPS score classification range (36.4\% and $44 \%$, respectively).

Conclusion. Our study found that IP feelings were common among responding student pharmacists and faculty members at the institutions surveyed, though little is known currently about the implications of these findings. Future research should seek to elucidate factors predictive of or associated with IP as well as assess the impact of strategies to prevent or manage IP.

Keywords: impostor phenomenon, professional development, student pharmacists, pharmacy faculty

\section{INTRODUCTION}

Impostor phenomenon (IP) describes an internal experience of intellectual fraudulence, which is often experienced by high-achieving individuals. "Impostors" can suffer from chronic self-doubt that overrides feelings of success or external proof of their competence. ${ }^{2}$ Pharmacists are a crucial part of the health care team and are considered medication experts. Work responsibilities for pharmacists include activities that often require intense critical thinking and high stakes decisions in fast-paced environments. Accordingly, pharmacists understandably place much importance and value in their work contributions and feelings of self-worth. Multiple contributing factors to IP in health professionals have been suggested including gender, religion, demographic factors, cultural factors, familial factors, and training environment. ${ }^{3,4}$ While not much literature exists in pharmacy to date, studies point to a high prevalence of IP in other health professions, (primarily medicine) though not associated with years of training, age, and most demographics. ${ }^{3,5-7}$ Furthermore, many pharmacists may have difficulty formulating their professional identity (a sense of how one views oneself combined with how others see them). Difficulty in accepting one's professional identity may further contribute to fraudulent feelings. 8 ,9

The IP phenomenon also involves a constant fear of exposure, isolation and rejection. ${ }^{10}$ While internal factors such as anxiety and depression can negatively affect those who experience IP, these feelings can cause external consequences. ${ }^{3,5-7}$ For example, IP may have an impact on one's career trajectory such as indecisiveness, avoiding responsibilities, self-sabotage, inability to delegate, postponing deadlines, and many more self-limiting issues. Left 
unchecked and allowed to fester and propagate, these feelings can potentially further stymie career growth, impede innovation, and may limit corporate ladder progression. ${ }^{3,11}$

Given the potential effect that IP can have on personal and professional growth across disciplines and demographic groups, an appropriate first step is to examine the prevalence of IP in student pharmacists and faculty members. However, no literature has described IP in these populations. The objective of this pilot study was to describe the prevalence of IP in pharmacy faculty and student pharmacists at two Doctor of Pharmacy (PharmD) programs in the midwestern US.

\section{METHODS}

A 49-question self-report survey instrument was delivered anonymously using Qualtrics software (Provo, UT) from April 2020 to May 2020. Subjects in this cross-sectional study included student pharmacists and faculty members at Sullivan University College of Pharmacy and Health Sciences (SUCHOPHS) in Louisville, Kentucky (a three-year accelerated PharmD program) and Northeast Ohio Medical University College of Pharmacy (NEOMED) in Rootstown, Ohio (a traditional four-year PharmD program). These programs were selected to implement this exploratory research because they are the home institutions of the authors. Branching logic was employed to funnel faculty members and student pharmacists to receive the appropriate demographic questions (for example, asking faculty members their academic rank vs. asking student pharmacists their professional year in the program). Survey completion time was estimated at 8-10 minutes (as estimated by the survey software), and participants were able to enter a raffle for one of five $\$ 100$ Amazon.com gift cards upon survey completion. This study was approved as exempt by the institutional review boards of both programs.

The Clance Impostor Phenomenon Scale (CIPS) is a 20-item self-report instrument which asks respondents to rate each statement on a Likert-type scale of 1 (not at all true) to 5 (very true). ${ }^{12,13}$ Example statements include, "I can give the impression that I'm more competent than I really am" and "I tend to remember the incidents in which I have not done my best more than those times I have done my best." All items are identically scored, and the score is reported as the sum of all ratings (minimum $=20$, maximum $=100$ ). Scores of 40 or less are characterized as "few" symptoms of IP, scores 41 60 as "moderate," 61-80 as "frequently," and scores over 80 represent "intense" IP symptoms. This scale was chosen over others because it has been used extensively over nearly 40 years of research in a variety of populations and was free to use for research purposes. The full text of the CIPS is available online at

https://paulineroseclance.com/impostor_phenomenon.html. Of note, limited background information was provided about IP to potential study subjects prior to the survey request other than the name of the instrument to prevent the potential for selection bias should individuals learn about IP via our survey and elect to participate because they may have believed they were experiencing the symptoms of IP.

The 49-question instrument included relevant demographic items to use for analysis purposes including age range and gender as well as two additional self-report scales not directly related to the topic of this study. An additional item on the instrument was included to assess professional identity formation prior to either professional training (for student pharmacists) or becoming a faculty member (as a type of professional) to determine if the feeling of alignment between one's view of oneself and others' view of them was associated with CIPS scores. ${ }^{8}$ Due to the lack of a widely accepted means of evaluating professional identity development in student pharmacists or faculty members, a simple "Yes/No" question was included (In your experience prior to pursuing pharmacy, have you developed an alternative professional identity?) in the survey instrument as a pilot to determine if the concept would be worth further examination. Respondents were not instructed or guided on how to interpret this item.

Survey responses were downloaded from Qualtrics into a spreadsheet for further analysis. Statistics were performed using Microsoft Excel 2016 (Microsoft, Redmond, WA) and IBM SPSS Statistics, version 23 (Armonk, NY). Demographics were reported as mean (SD) or raw numbers with percentages as appropriate for type of data. CIPS results were reported as sum of the numerical rating of all responses (with mean and SD for the different cohorts). Results from the demographic groups were compared using Student's $t$ tests. CIPS scores were sorted into the respective classifications as noted previously (ie, "few," "moderate").

\section{RESULTS}

Our overall response rate to the survey including both institutions and counting student pharmacists and faculty members together was 35.5\% (209/589). That overall response rate was slightly higher for SUCOPHS at 40.5\% (85/210) vs. $32.7 \%$ for NEOMED (124/379). For student pharmacists, our overall response rate was 33.9\% (174/514), which was higher for SUCOPHS at 39.6\% (72/182) vs. NEOMED at 30.7\% (102/332). For faculty, the overall response rate was $46.7 \%$ (35/75), which was similar between programs with NEOMED at 46.8\% (22/47) and SUCOPHS at 46.4\% (13/28). 
Demographic characteristics for student pharmacist respondents are listed in Table 1. Most student pharmacists were ages 25 and under or 26-30 (55.7\% and 31\%, respectively), which was similar between programs. Most student pharmacists who responded identified as female $(70.7 \%)$, which was also similar between programs. Student pharmacist respondents were overall evenly distributed among years of the respective programs, though the differing nature of the programs (ie, SUCOPHS as a three-year PharmD program and NEOMED being a four-year PharmD program) prevented significant interpretation of year in program as a delineating demographic characteristic. Most student pharmacist respondents (68.4\%) reported no alternative professional identity prior to pharmacy school. Demographic characteristics for faculty respondents are listed in Table 2. Most faculty members who responded to the survey were ages 31-35, with that proportion slightly higher at NEOMED vs. SUCOPHS (31.8\% and 23.1\%, respectively). The next largest age group for faculty respondents was ages $41-45$, where $20 \%$ of the overall faculty respondents fell. Most faculty respondents overall $(57.1 \%)$ identified as female, though this was different between institutions $(\mathrm{p}=0.03)$. The overwhelming majority $(84.6 \%)$ of faculty respondents from SUCOPHS identified as female, whereas less than half $(40.9 \%)$ of the faculty respondents from NEOMED identified as female. Faculty respondents overall were evenly split between assistant and associate professor ranks (42.9\% for each), with a minority $(11.4 \%)$ as full professors. Most faculty respondents overall $(62.9 \%)$ reported no administrative rank, and $60 \%$ reported practicing pharmacy in their current position. The overwhelming majority of overall faculty respondents $(77.1 \%)$ reported having no alternative professional identity prior to becoming a faculty member.

The overall mean CIPS score for all survey respondents $(\mathrm{N}=209)$ was $63.8(\mathrm{SD}=15.1)$. Overall mean CIPS score for NEOMED was 63.7 ( $\mathrm{SD}=14.4)$ vs. 63.9 ( $\mathrm{SD}=16.1$ ) for SUCOPHS, which was similar $(p=.92)$. Mean student pharmacist CIPS score for NEOMED was 64.7 ( $\mathrm{SD}=14.4)$ vs. $63.8(\mathrm{SD}=16.1)$ for SUCOPHS, which was similar $(p=.70)$. Mean faculty CIPS score for NEOMED was 59.2 ( $\mathrm{SD}=14.0)$ vs. $64.7(\mathrm{SD}=16.8)$ for SUCOPHS, which was similar $(p=.32)$. Mean CIPS score for the combined student pharmacist group (NEOMED and SUCOPHS) was 64.3 (SD=15.1) vs. $61.2(\mathrm{SD}=15.1)$ for the combined group of faculty members, which was similar $(p=.26)$.

Results indicate that the highest percentage of respondents were classified as having moderate to frequent IP symptoms based on the CIPS score classifications, as shown in Table 3. The largest proportion of respondents overall (44\%, including both student pharmacists and faculty) were classified as having frequent feelings of IP (defined as a CIPS score of 61-80). Only 6.2\% (13/209) of all respondents were classified as having "few" feelings of IP (defined as a CIPS score $\leq 40)$, which was the lowest Only $13.4 \%$ (28/209) of all respondents were classified as having intense feelings of IP (defined as a score $>80$ on the CIPS), with the proportion of student pharmacists and faculty reporting this level of IP ranging 12.1-15.4\%.

\section{DISCUSSION}

To our knowledge, this is the first study evaluating the prevalence and severity of IP in pharmacy faculty. Our findings also expand on preliminary data demonstrating the prevalence and severity of IP in student pharmacists. Henning et al (1998) conducted a study of medicine, dental, nursing, and pharmacy students $(n=477)$ and demonstrated that the overall IP prevalence was 30.2\%. ${ }^{7}$ Mean CIPS score for student pharmacists in this study indicated that respondents had "moderate" IP symptoms. ${ }^{7}$ While Henning et al was notable for its large sample population and inclusion of multiple health professions students, a significant limitation for use of Henning et al currently is that it was conducted at a time when a bachelor's degree was the minimum requirement to practice. Pharmacist training has significantly changed since the time this data was published, as doctorate level-training became a requirement in $2000 .{ }^{14}$ The transition to all PharmD curriculum significantly changed the landscape of pharmacy education and continued efforts already underway prior to that shift to transition pharmacy from product-oriented to more focused on patient care. It would be difficult to ascertain if curricular and practice transformations since 2004 would affect the prevalence or severity of IP in student pharmacists.

Legassie et al (2008) also demonstrated that health care professionals experience IP during post-graduate training. ${ }^{6}$ In their study evaluating IP feelings during medical residency $(n=48)$ determined that $43.8 \%$ of respondents experienced IP feelings, with higher scores in residents who were foreign-trained or at later stages of their training. ${ }^{6}$ Accordingly, Oriel et al (2004) conducted a survey of family medicine residents $(n=185)$ which concluded that $41 \%$ of women and $24 \%$ of men scored as "imposters" on the CIPS and that imposter symptoms were highly correlated with depression $\left(r^{2}=.45, p<.001\right)$ and anxiety $\left(r^{2}=.65, p<.001\right) .{ }^{5}$ The researchers also concluded that about one third of family medicine residents believe they are less intelligent and less competent than others perceive them to be. ${ }^{5}$ Sullivan et al (2020) focused on describing IP in pharmacy residents $(n=720)$ and found that 57.5\% experienced IP feelings with positive correlations to receiving prior treatment for a mental health condition and longer work hours. ${ }^{15}$ These authors also described that CIPS score and the Mayo Clinic Residency Well-Being Index were weakly but significantly correlated $(\varrho=.357 ; p<.001) .{ }^{15}$ The Mayo Clinic Residency Well-Being Index is a 7-item validated tool that is utilized to assess 
distress in medical residents, alluding to the possibility that IP feelings could be associated with feelings of burnout. ${ }^{15}$ While this evidence provides support for IP feelings emerging during post-graduate training, literature is lacking regarding IP that may occur during one's academic career or at later stages in a pharmacist's career.

Strengths of this study included cross-institutional collaboration, unique study populations of student pharmacists and pharmacy faculty, and the use of a validated survey tool to determine IP prevalence. To our knowledge, this study represents the first published study on IP to include pharmacy faculty members. While preliminary in nature, this information could also potentially be helpful in the professional development of student pharmacists and pharmacy faculty members. Larger, more comprehensive studies of IP in pharmacy faculty members are needed to fully understand this issue and its scope.

There are several important limitations of this study to note. First, like all survey research, non-response bias could have occurred based on non-responders lacking interest in the subject or having not experienced feelings of IP. ${ }^{16}$ Additionally, our study had a relatively small sample size due to the limited response rate (35.5\% overall). However, our response rate and overall number of respondents were similar to several previously published studies in the area (which ranged from $18.7 \%$ to $48 \%$ response rate) and reflected a diversity of demographic groups. ${ }^{7,15}$ Another important limitation is related to how potential survey respondents perceived the survey and their baseline knowledge of IP. As noted earlier, limited information was provided to potential survey respondents about IP to mitigate or minimize selection bias. Thus, it is possible that individual survey respondents had entirely disparate internal conceptions of IP and therefore approached the survey from different baseline levels of knowledge and understanding. The net impact or effect of this decision on our study is impossible to determine but worth noting in interpreting the results. Finally, while the CIPS instrument has been used for decades across multiple demographic groups, it is possible that respondents may have interpreted the wording of various items differently than what was intended (a type of framing bias). This challenge is not unique to our study or its design, however, and it is impossible to know how or if such differences in interpretation would impact the results. ${ }^{17-18}$ One unique confounder to our study that could have affected both the response rate and potential interpretation of the results was the timing of survey administration. This survey was completed during the early stages of the COVID-19 pandemic in April 2020 to May 2020, just as national and local lockdowns were in effect and many educational institutions switched to virtual learning. It is unclear, however, what (if any) effect this could have had on the results, though it is certainly possible that specific circumstances of that period could have affected how respondents perceived their abilities.

These findings may have implications on how colleges and schools of pharmacy approach professional development for student pharmacists and pharmacy faculty. It may be hypothesized that implications of these findings could impact academic or professional success, job satisfaction, self-efficacy, work engagement, and/or propensity for burnout as individuals may work harder to "prove themselves" due to having fraudulent feelings. ${ }^{19,20}$ However, evidence of such associations would need to be investigated and documented to draw definitive conclusions. It also may be interesting to explore how IP feelings change throughout one's academic or professional career as well as what demographic or environmental factors correlate with IP results. Additionally, surveying a larger and more diverse population may bring to light consistent or new findings regarding IP prevalence and severity within the profession and in pharmacy education.

\section{CONCLUSION}

Our study found that IP feelings are common among responding pharmacy faculty members and student pharmacists at the surveyed institutions, with most student pharmacists and faculty reporting IP symptoms that fell into the "moderate" or "frequent" classification. However, little is known currently about the implication of those classifications. Future research should seek to elucidate factors predictive of IP in student pharmacists and faculty members as well as evaluate potential mitigation strategies that could be employed by programs or individuals to prevent or manage feelings of IP.

\section{REFERENCES}

1. Clance PR, Imes SA. The imposter phenomenon in high achieving women: Dynamics and therapeutic intervention. Psychother- T. 1978;15(3):241- 247.

2. Corkindale, G. Overcoming Imposter Syndrome. Harvard Bus Rev. May 7, 2008. https://hbr.org/2008/05/overcoming-imposter-syndrome. Accessed March 15, 2021.

3. Barrow JM. Impostorism: An evolutionary concept analysis. Nurs Forum. 2019;54(2):127-136.

4. Seritan AL, Mehta MM. Thorny Laurels: the Impostor Phenomenon in Academic Psychiatry. Acad Psychiatry. 2016;40(3):418-21. 
5. Oriel K, Plane MB, Mundt M. Family medicine residents and the impostor phenomenon. Fam Med. 2004;36(4):248-52.

6. Legassie J, Zibrowski EM, Goldszmidt MA. Measuring Well-Being: Impostorism and Burnout Syndrome in Residency. J Gen Intern Med. 2008;23(7):1090-4.

7. Henning K, Ey S, Shaw D. Perfectionism, the imposter phenomenon and psychological adjustment in medical, dental, nursing and pharmacy students. Med Educ. 1998;32(5):456-64.

8. Noble C, McKauge L, Clavarino A. Pharmacy student professional identity formation: a scoping review. Integr Pharm Res Pract. 2019;8:15-34.

9. Persky AM. Intellectual Self-doubt and How to Get Out of It. Am J Pharm Educ. 2018;82(2):Article 6990.

10. White SJ. Perfectionism: A Stumbling Block to Effective Leadership? (Every Pharmacist Must be a Leader). Hosp Pharm. 2016;51(6):429-430.

11. Neureiter M, Traut-Mattausch E. Inspecting the Dangers of Feeling like a Fake: An Empirical Investigation of the Impostor Phenomenon in the World of Work. Front Psychol. 2016;7:1445.

12. Clance Impostor Phenomenon Scale (CIPS). From The Impostor Phenomenon: When Success Makes You Feel Like A Fake (pp. 20-22), by P.R. Clance, 1985, Toronto: Bantam Books. Copyright 1985 by Pauline Rose Clance, Ph.D., ABPP. Use by permission of Dr. Pauline Rose Clance. Do not reproduce/copy/distribute without permission from Pauline Rose Clance, drpaulinerose@comcast.net, www.paulineroseclance.com.

13. Clance PR. The Impostor Phenomenon: When Success Makes You Feel Like a Fake. Atlanta: Peachtree Publishers; 1985.

14. Francisco G. Doctor of Pharmacy. In: Dipiro J, ed. Encyclopedia of Clinical Pharmacy. New York: Marcel Dekker; 2003.

15. Sullivan JB, Ryba NL. Prevalence of impostor phenomenon and assessment of well-being in pharmacy residents. Am J Health Syst Pharm. 2020;77(9):690-696.

16. Jones TL, Baxter MA, Khanduja V. A quick guide to survey research. Ann R Coll Surg Engl. 2013;95(1):5-7.

17. Ballard A. Framing Bias in the Interpretation of Quality Improvement Data: Evidence From an Experiment. Int $J$ Health Policy Manag. 2019;8(5):307-314.

18. Colditz GA. Overview of the epidemiology methods and applications: strengths and limitations of observational study designs. Crit Rev Food Sci Nutr. 2010;50 Suppl 1(s1):10-2.

19. Yu JH, Chae SJ, Chang KH. The relationship among self-efficacy, perfectionism and academic burnout in medical school students. Korean J Med Educ. 2016;28(1):49-55.

20. Alrayyes S, Dar UF, Alrayes M, Alghutayghit A, Alrayyes N. Burnout and imposter syndrome among Saudi young adults. The strings in the puppet show of psychological morbidity. Saudi Med J. 2020;41(2):189-194. 
Table 1. Demographics of All Student Respondents to the Clance Impostor Phenomenon Scale (CIPS) ${ }^{\mathrm{a}}$ Survey $(\mathrm{N}=174)$

\begin{tabular}{|c|c|c|c|}
\hline & $\begin{array}{l}\text { All }(n=174) \\
\text { n }(\%)\end{array}$ & $\begin{array}{l}\text { SU COPHS }(n=72) \\
n(\%)\end{array}$ & $\begin{array}{l}\text { NEOMED }(\mathrm{n}=102) \\
\text { n }(\%)\end{array}$ \\
\hline \multicolumn{4}{|l|}{ Age } \\
\hline 25 and under & $97(55.7)$ & $41(56.9)$ & $56(54.9)$ \\
\hline $26-30$ & $54(31)$ & $23(31.9)$ & $31(30.4)$ \\
\hline $31-35$ & $16(9.2)$ & $6(8.3)$ & $10(9.8)$ \\
\hline $36-40$ & $4(2.3)$ & $1(1.4)$ & $3(2.9)$ \\
\hline $41-45$ & $1(.6)$ & $1(1.4)$ & $0(0)$ \\
\hline $46-50$ & $1(.6)$ & $0(0)$ & $1(1)$ \\
\hline 51 and above & $0(0)$ & $0(0)$ & $0(0)$ \\
\hline Prefer not to respond & $0(0)$ & $0(0)$ & $1(1)$ \\
\hline \multicolumn{4}{|l|}{ Gender } \\
\hline Male & $48(27.6)$ & $21(29.2)$ & $27(26.5)$ \\
\hline Female & $123(70.7)$ & $50(69.4)$ & $73(71.6)$ \\
\hline Non-binary/third gender & $1(.6)$ & $0(0)$ & $1(1)$ \\
\hline Prefer to self-describe & $0(0)$ & $0(0)$ & $0(0)$ \\
\hline Prefer not to say & $2(1.1)$ & $1(1.4)$ & $1(1)$ \\
\hline \multicolumn{4}{|l|}{ Professional year ${ }^{\mathrm{b}}$} \\
\hline First & $36(20.7)$ & $19(26.4)$ & $17(16.7)$ \\
\hline Second & $55(31.6)$ & $24(33.3)$ & $31(30.4)$ \\
\hline Third & $54(31.0)$ & $29(40.3)$ & $25(24.5)$ \\
\hline Fourth (NEOMED only) & $29(16.7)$ & $\mathrm{N} / \mathrm{A}^{*}$ & $29(28.4)$ \\
\hline \multicolumn{4}{|c|}{ Alternative Professional Identity } \\
\hline Yes & $55(31.6)$ & $26(36.1)$ & $29(28.4)$ \\
\hline No & $119(68.4)$ & $46(63.9)$ & $73(71.6)$ \\
\hline
\end{tabular}

SUCOPHS=Sullivan University College of Pharmacy and Health Sciences; NEOMED = Northeast Ohio Medical University ${ }^{\text {a }}$ The CIPS is a 20-item self-report instrument which asks respondents to rate each statement on a Likert-type scale of 1 (not at all true) to 5 (very true). All items are identically scored, and the score is reported as the sum of all ratings (minimum $=20$, maximum $=100)$.

${ }^{\mathrm{b}}$ SUCOPHS is a three-year pharmacy program and NEOMED is a four-year pharmacy program. 
Table 2. Demographics of All Faculty Member Respondents to the Clance Impostor Phenomenon Scale (CIPS) $)^{\text {a }}$ Survey $(\mathrm{N}=35)$

\begin{tabular}{|c|c|c|c|}
\hline & $\begin{array}{l}\text { All }(n=35) \\
\text { n }(\%)\end{array}$ & $\begin{array}{l}\text { SU COPHS }(n=13) \\
n(\%)\end{array}$ & $\begin{array}{l}\text { NEOMED }(n=22) \\
\text { n }(\%)\end{array}$ \\
\hline \multicolumn{4}{|l|}{ Age } \\
\hline 25 and under & $2(5.7)$ & $0(0)$ & $2(9.1)$ \\
\hline $26-30$ & $3(8.6)$ & $0(0)$ & $3(13.6)$ \\
\hline $31-35$ & $10(28.6)$ & $3(23.1)$ & $7(31.8)$ \\
\hline $36-40$ & $6(17.1)$ & $3(23.1)$ & $3(13.6)$ \\
\hline $41-45$ & $7(20)$ & $2(15.4)$ & $5(22.7)$ \\
\hline $46-50$ & $3(8.6)$ & $3(23.1)$ & $0(0)$ \\
\hline 51 and above & $4(11.4)$ & $2(15.4)$ & $2(9.1)$ \\
\hline Prefer not to respond & $0(0)$ & $0(0)$ & $0(0)$ \\
\hline \multicolumn{4}{|l|}{ Gender } \\
\hline Male & $14(40)$ & $2(15.4)$ & $12(54.5)$ \\
\hline Female & $20(57.1)$ & $11(84.6)$ & $9(40.9)$ \\
\hline Non-binary/third gender & $0(0)$ & $0(0)$ & $0(0)$ \\
\hline Prefer to self-describe & $0(0)$ & $0(0)$ & $0(0)$ \\
\hline Prefer not to say & $1(2.9)$ & $0(0)$ & $1(4.5)$ \\
\hline \multicolumn{4}{|l|}{ Academic Rank } \\
\hline Professor & $4(11.4)$ & $4(30.8)$ & $0(0)$ \\
\hline Associate Professor & $15(42.9)$ & $6(46.2)$ & $9(40.9)$ \\
\hline Assistant Professor & $15(42.9)$ & $3(23.1)$ & $12(54.5)$ \\
\hline Lecturer & $0(0)$ & $0(0)$ & $0(0)$ \\
\hline Instructor & $1(2.9)$ & $0(0)$ & $1(4.5)$ \\
\hline \multicolumn{4}{|l|}{ Administrative Rank } \\
\hline Dean & $0(0)$ & $0(0)$ & $0(0)$ \\
\hline Associate Dean & $1(2.9)$ & $0(0)$ & $1(4.5)$ \\
\hline Assistant Dean & $2(5.7)$ & $2(15.4)$ & $0(0)$ \\
\hline Department Head/Chair & $2(5.7)$ & $0(0)$ & $2(9.1)$ \\
\hline Other & $8(22.9)$ & $3(23.1)$ & $5(22.7)$ \\
\hline No Administrative Rank & $22(62.9)$ & $8(61.5)$ & $14(63.6)$ \\
\hline \multicolumn{4}{|c|}{ Practice Pharmacy in Current Position? } \\
\hline Yes & $21(60)$ & $6(46.2)$ & $15(68.2)$ \\
\hline No & $14(40)$ & $7(53.8)$ & $7(31.8)$ \\
\hline \multicolumn{4}{|c|}{ Alternative Professional Identity } \\
\hline Yes & $8(22.9)$ & $6(46.2)$ & $2(9.1)$ \\
\hline No & $27(77.1)$ & $7(53.8)$ & $20(90.9)$ \\
\hline
\end{tabular}

SUCOPHS=Sullivan University College of Pharmacy and Health Sciences; NEOMED = Northeast Ohio Medical University

${ }^{\text {a }}$ The CIPS is a 20-item self-report instrument which asks respondents to rate each statement on a Likert-type scale of 1 (not at all true) to 5 (very true). All items are identically scored, and the score is reported as the sum of all ratings $($ minimum $=20$, maximum $=$ $100)$. 
Table 3. Clance Impostor Phenomenon Scale (CIPS) ${ }^{\text {a }}$ Results of Student Pharmacists and Faculty Members by Institution and Score Classification $(\mathrm{N}=209)$

\begin{tabular}{|c|c|c|c|c|c|c|c|}
\hline & \multirow[b]{2}{*}{ All } & \multicolumn{2}{|c|}{ SUCOPHS $(n=85)$} & & \multicolumn{2}{|c|}{ NEOMED $(n=124)$} & \multirow[b]{2}{*}{$\begin{array}{l}\text { Faculty } \\
(n=22) \\
n(\%)\end{array}$} \\
\hline & & $\begin{array}{l}\text { Overall } \\
(\mathrm{n}=85) \\
\mathrm{n}(\%)\end{array}$ & $\begin{array}{l}\text { Students } \\
(\mathrm{n}=72) \\
\mathrm{n}(\%)\end{array}$ & $\begin{array}{l}\text { Faculty } \\
(\mathrm{n}=13) \\
\mathrm{n}(\%)\end{array}$ & $\begin{array}{l}\text { Overall } \\
\mathrm{n}(\%)\end{array}$ & $\begin{array}{l}\text { Students } \\
(\mathrm{n}=102) \\
\mathrm{n}(\%)\end{array}$ & \\
\hline $\begin{array}{l}\text { Classifications (with } \\
\text { ranges) }\end{array}$ & & & & & & & \\
\hline Few $(\leq 40)$ & $13(6.2)$ & $7(8.2)$ & $5(6.9)$ & $2(15.4)$ & $6(4.8)$ & $3(2.9)$ & $3(13.6)$ \\
\hline Moderate (41-60) & $76(36.4)$ & $31(36.5)$ & $28(38.9)$ & $3(23.1)$ & $45(36.3)$ & $37(36.3)$ & $8(36.4)$ \\
\hline Frequent (61-80) & $92(44)$ & $34(40)$ & $28(38.9)$ & $6(46.2)$ & $58(46.8)$ & $47(46.1)$ & $11(50)$ \\
\hline Intense $(>80)$ & $28(13.4)$ & $13(15.3)$ & $11(15.3)$ & $2(15.4)$ & $15(12.1)$ & $15(14.7)$ & $0(0)$ \\
\hline
\end{tabular}

SUCOPHS = Sullivan University College of Pharmacy and Health Sciences; NEOMED = Northeast Ohio Medical University

${ }^{\text {a }}$ The CIPS is a 20-item self-report instrument which asks respondents to rate each statement on a Likert-type scale of 1 (not at all true) to 5 (very true). All items are identically scored, and the score is reported as the sum of all ratings (minimum $=20$, maximum $=100)$. 